\section{The Discovery of Radioactivity}

\section{P. Radvanyi}

Laboratoire National Saturne, Gif-sur-Yvette, France

\section{A few major and completely unexpected experimental discoveries revolutionized physical understanding 100 years ago.}

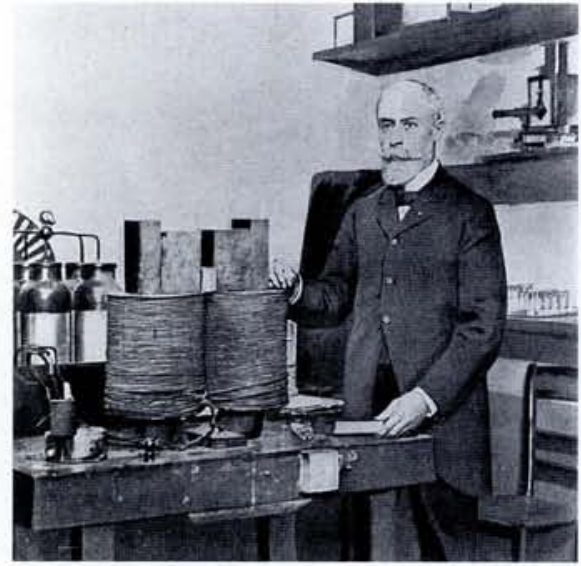

Henri Becquerel

As the 19th century progressed, atoms imposed more and more their existence to chemists and physicists, starting in 1803 with the revival and reformulation by John Dalton in Manchester of the atomic hypothesis of the ancient Greek philosophers on the basis of the properties of the chemical elements and their compounds. It took time - and the efforts, for instance, of the Frenchmen J.L. Proust and L.J. GayLussac and the Italians A. Avogadro and S. Cannizzaro - to accept the atomic model, to distinguish atoms from molecules. By the beginning of the 1890 s, atoms were being invoked to describe the macroscopic properties of bulk matter; it was, however, not yet possible to study experimentally

Pierre Radvanyi is presently Directeur de recherche émérite in the Centre National de Recherche Scientifique (CNRS), Laboratoire National Saturne, DSM/CEA- $\ln _{2} \mathrm{P}_{3} /$ CNRS, F-91191 Gif-sur-Yvette Cedex. He received his DSC in 1954 from the University of Paris and then worked on radioactivity and nuclear reactions at the Collège de France and the Institut de Physique Nucléaire, Université de Paris-Sud, Orsay. He carried out experiments at Saclay's Linear Electron Accelerator and the Saturne synchrotron, and served as Deputy Director of the Laboratoire National Saturne in 1978-85. Professor Radvanyi coauthored (with M. Bordry) La radioactivité artificielle et son histoire (1984) and Histoire d'atomes (1988) and was the author of Les rayonnements nucléaires (1995). He has edited the Bulletin de la Société Française de Physique since 1969 and was the Society's Secretary General in 1975-80.

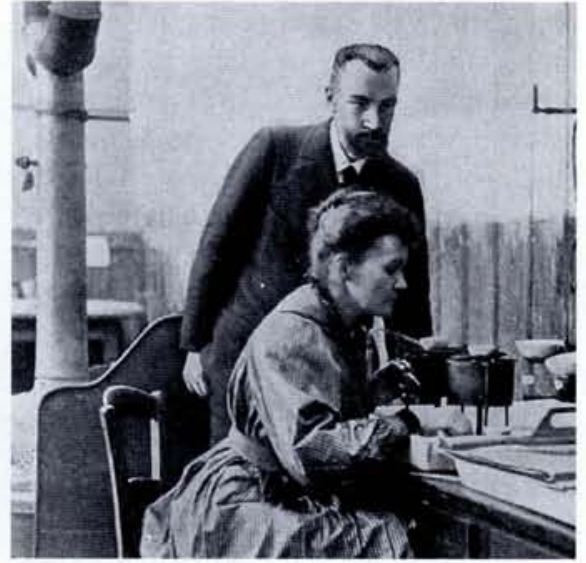

Pierre and Marie Curie

the constituent atoms and to explore their structure. In the meantime, scientific instruments and experimental methods had developed and improved considerably: very small amounts of electric charge could be measured, a high vacuum had been achieved in glass tubes, and highvoltage discharges were being exploited.

Suddenly, a few major and completely unexpected experimental discoveries revolutionised our physical understanding and allowed us to enter inside the atom. The consequences were tremendous.

In November 1895 , Wilhelm C. Röntgen discovered $\mathrm{X}$ rays at the University of Würzburg. On January 1st, 1896, he sent a description of his results and copies of his first radiographs to several leading European scientists. Henri Poincaré showed one of these radiographs, as well as the first medical X-rays radiographs taken in France, to his colleagues at the Academy of Sciences in Paris, on January 20th, 1896. Röntgen had shown that the Xrays originated from the portion of the glass tube on which cathode rays impinged. This portion of glass was also strongly luminescent and Poincaré suggested that the emission of X-rays and luminescence were associated phenomena.

\section{Becquerel Rays}

Henri Becquerel, Professor at the Muséum d'Histoire Naturelle and member of the Academy, a specialist on lumines- cence, took note of the remark on the possible link between X-rays and luminescence. On returning to his laboratory on the rue Cuvier, he designed an experiment to test the hypothesis that X-ray emission and luminescence were related. In order to see if a phosphorescent body emitted Xrays, he chose the hydrated salt $\left[\mathrm{SO}_{4}(\mathrm{UO}) \mathrm{K}+\mathrm{H}_{2} \mathrm{O}\right]$, as originally written by Bordry, which he had prepared some years before with his father Edmond Becquerel, who himself had been a wellknown specialist on luminescence in the museum. On February 2oth, Henri Becquerel placed a transparent crystal of the salt on a photographic plate wrapped inside two thick sheets of black paper, the whole set-up being exposed to sunlight for several hours. After development, the silhouette of the crystal appeared in black on the photograph. Becquerel concluded that the phosphorescent substance emitted a penetrating radiation which was able to pass through black paper [1].

Becquerel wanted to repeat this experiment using different types and thicknesses of absorbers. But the Sun did not shine on Paris on either Wednesday, February 26 th or Thursday, February 27 th. So he put away his salt placed on the undeveloped photographic plates in a drawer, and as the Sun did not appear on 1st March he developed the plates in order to find out the amount by which the phosphorescence had decreased (photographic emulsions integrate radiation over time). He was surprised to find that the phosphorescence had not decreased but was more intense than on the first day. He immediately thought that the salt's activity had continued in the dark. He also noted a shadow from a piece of metal he had introduced between the salt and the plate.

Clearly, sunlight was unnecessary for the emission of the penetrating rays. Becquerel soon underlined the resemblances and differences between $\mathrm{X}$-rays and the radiation he had discovered [2].

The activity of his uranium salt did not diminish with time, even after several months. Becquerel thought that the rays he was detecting were either hard X-rays or phosphorescence of long duration. Using an electroscope, he observed furthermore that the rays were able to "electrify" air (today we say "ionize"). There was no difference in the intensity of the radiation after melting and recrystallising the salt. On May 18 th, he noted that a nonphosphorescent uranium salt also emitted radiation (he discovered that it was the element uranium which was responsible). 
On November 23rd, Becquerel remarked: "We do not know yet where uranium takes out the energy which it emits with such a long persistence." He called his rays "uranic rays"; other scientists were to call them Becquerel rays. On April 12th, 1897 , Becquerel observed that the intensity of radiation from his salt had not decreased over an entire year. He then decided to stop - provisionally - his experiments on uranium in order to work on a new topic, the Zeeman effect, which had been discovered a few months before.

\section{Polonium and Radium}

A few months later, at the end of 1897 , after the birth of her first daughter Irène, Marie Curie-Sklodowska wanted to start work for a doctorat d'état in physics (she was to be the first woman to obtain such a degree in France). She had come from Warsaw to Paris to study at the Sorbonne as women were not admitted to Polish universities at the time. She had married Pierre Curie, who had already made his reputation with his work on piezoelectricity, symmetry and magnetism. After discussing the matter with her husband, Marie Curie decided to study Becquerel rays. Pierre Curie obtained from the Director of the Ecole de Physique et Chimie Industrielles de la ville de Paris where he was professor, permission for his wife to use an empty workshop in this engineering school. Marie Curie started her work in December by first setting up equipment to perform quantitative measurements of the new radiation. It consisted of an electrometer, a simple ionization chamber and a piezoelectric quartz crystal which had been developed by Pierre and his brother Jacques. The electric charge created in the quartz compensated, for a given time, the charge generated by the radiation in the ionization chamber.

Marie Curie studied large numbers of elements, chemical compounds and minerals in seeking radiation of the same type as that discovered by Becquerel. Independently of G. Schmidt, she found that thorium exhibited the same properties as uranium. The emission of radiation was thus a general property of matter and Marie Curie devised the word "radioactivity" to describe this feature. She also found that several uranium minerals, in particular pitchblende and chalcolite, were much more active than uranium itself, while synthetic minerals possessed the same level of activity as uranium. Marie Curie concluded that these minerals contained a very active unknown element [3]. She also
The early part of the uranium-radium decay series, showing the direct daughter products (originally designated $U X_{1}, U X_{2}, U \|$, and Io) of uranium 238. The uranic rays which allowed Becquerel to discover radioactivity were actually the $\beta$-rays emitted by uranium $X_{1}$ (thorium 234) and uranium $X_{2}$ (protactinium $234 \mathrm{~m}$ ).

noted that radioactivity appeared to be an atomic property.

Pierre Curie abandoned the work on crystals he was carrying out at the time and decided to join his wife in the search for the unknown radioactive element. This element, which exhibited some chemical similarities with bismuth, appeared to be present in minute quantities and measurement of the emitted radiation was the only way to follow it during successive chemical separations (the radioactivity became stronger and stronger until it reached more than 400 times the activity of uranium). They called the new radioactive element polonium in honour of Marie Curie's country of origin [4].

Once polonium and bismuth had been removed from the solutions, the remaining liquid remained radioactive. Pitchblende appeared thus to contain a second very active but unknown element which had chemical properties distinct from those of polonium and seemed to be analogous to barium. Together with the chemist Gustave Bémont, the Curies endeavoured to separate it. They succeeded in obtaining it in the form of radioactive barium chloride, which they redissolved and reprecipitated from solution time and time again, thereby obtaining increasingly active barium chloride. They asked the physicist Eugène Demarçay to examine the optical spectrum of their active substance. Demarçay found a very weak, unknown line when the chloride was 60 times more active than uranium; the line became stronger with the gradual enrichment, until the chloride was 900 times as active as uranium. The Curies called this new radioactive element radium [5].

Radium was the most active of the newly found radio-elements which one could observe directly and weigh (there is one gm of radium in approximately 2.8 tonnes of natural uranium). Radium was to play a key role in the understanding of the radioactive series. The radiation from radium and its daughter products became a formidable tool in the microscopic exploration of matter and the internal structure of its atoms. It was to open up of new fields of research as well as applications one could not even dream of before radioactivity had been discovered.

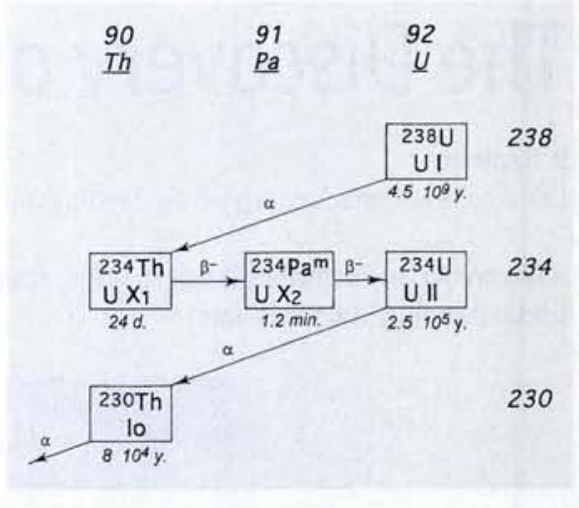

\section{Radiation, Emanation and Excited Radioactivity}

A number of scientists, including Becquerel and Pierre and Marie Curie, now went on to study the properties of the radiation emitted by the different radioelements. By January 1899, Ernest Rutherford was able to show that the radiation emitted by uranium is complex, consisting of easily absorbed rays ( $\alpha$-rays) and more penetrating rays (the $\beta$-rays). In 1900, $\mathrm{P}$. Villard observed the presence of the extremely penetrating $\gamma$-rays. In Europe, $\beta$-rays were called deviating rays for a few years (since they were deviated by a magnetic field) while $\alpha$-rays were called nondeviating rays. Other radio-elements were also discovered, such as actinium by André Debierne in 1899, and uranium X (a direct daughter product of uranium) by William Crookes in 1900.

Converging studies in Germany, Austria and France eventually arrived at the conclusion that $\beta$-rays are energetic electrons. Rutherford was to demonstrate a short while later that $\alpha$-rays consist of fully ionized helium atoms carrying two positive charges. It is perhaps curious that Henri Becquerel never recognized the emission of $\alpha$-rays by uranium. In his Nobel Lecture on December 11th, 1903, he pointed out that he had shown "that, even in vacuum, uranium emits only $\beta$-rays", except possibly for the existence of much lower level of activity due to $\gamma$-rays. Becquerel had looked for the emission of $\alpha$ rays by uranium, but had not succeeded in observing it using his experimental set-up. The uranic rays which allowed Becquerel to discover radioactivity were actually the $\beta$-rays emitted by the direct daughter products of uranium, namely uranium $\mathrm{X}_{1}$ (thorium 234) and uranium $\mathrm{X}_{2}$ (protactinium $234 \mathrm{~m}$ ), in radioactive equilibrium with uranium 238 (see figure).

In November 1899, Pierre and Marie Curie make the astonishing discovery that any material - a sheet of zinc, aluminium 
or lead, or even a sheet of paper - placed in the neighbourhood of a strong radioactive source of radium, became radioactive. They called this new property "induced radioactivity”. It slowly disappeared, reaching one-tenth of its initial activity after two to three hours. They tried to wash off the activity from their metallic sheets, but it remained; the phenomenon was more reproducible and gave rise to a stronger effect when experiments were performed in a closed vessel.

At about the same time, Rutherford working in Montreal started experiments on thorium compounds. He discovered that thorium oxide seemed to give rise to a kind of radioactive vapour which he called an "emanation". He was able to follow the emanation along a long glass tube and to observe that half of the emanation disappeared in about one minute (it effectively behaved like a radioactive gas). Rutherford also observed that following exposure for a certain time to emanation, all bodies seemed to be covered by an invisible layer of a very radioactive material which he called "excited radioactivity"; scouring the surface with sandpaper removed the activity. This excited radioactivity looked very much like the induced radioactivity described by the Curies; it exhibited an exponential decrease in intensity, with a half-life - a term coined by Rutherford - of 11 hours. Rutherford was to write to his mother in 1901: "I have to publish my present work as rapidly as possible in order to keep in the race. The best sprinters in this road of investigation are Becquerel and the Curies in Paris who have done a great deal of very important work in the subject of radioactive bodies during the last few years."

Pierre Curie did not accept the explanation put forward by Rutherford. He had his own views on the nature of radioactivity, which he maintained for more than another two years. Only in June 1903 was he to adopt Rutherford's point of view. Rutherford in the meantime had performed a variety of new experiments to prove his hypothesis, and he had joined forces with the young chemist Frederick Soddy in order to probe further and to understand radioactivity.

\section{Radioactive Change}

Rutherford and Soddy soon established a number of new facts. The very active emanation was indeed an inert gas present in minute quantities [6]. Both thorium and radium gave rise to an emanation (the radium emanation had been observed for the first time by Ernst Dorn in 1900). Their latest conclusive evidence showed that both emanations condensed at the temperature of liquid air and possessed sharply defined temperatures for volatilization and condensation.

The two scientists found that they were able to separate chemically a new radio-element from thorium. They called it thorium $\mathrm{X}$ - the thorium resulting from this process being less than one-half as radioactive as the original (unseparated) material. It was thorium $\mathrm{X}$, and not thorium, which gave rise to the emanation. They also discovered that the activity of the separated thorium $\mathrm{X}$ decreased in time, with a half-life of a little less than four days, whereas during the same time the remaining thorium recovered its original activity with the same time constant: the sum of the two activities stayed constant [6]. There was no doubt: thorium transformed itself into thorium $\mathrm{X}$ which in turn transformed into the gaseous emanation and the emanation formed a solid, active deposit - the excited radioactivity. Radioactivity was thus a subatomic change - a spontaneous transmutation - through the emission of radiation. The energy of radioactive change appeared to be several hundred thousand times the energy of any chemical (i.e., molecular) reaction [7].

The third Nobel Prize in Physics was awarded jointly in 1903 to Henri Becquerel and to Pierre and Marie Curie. Pierre Curie concluded his 1905 Nobel Lecture in Stockholm in a premonitory way: "One can furthermore imagine that in criminal hands radium could become very dangerous and here one can ask if humanity is at an advantage in knowing Nature's secrets, if it is mature enough to make use of them or if this knowledge might not be harmful to it. The example of the discoveries of Nobel is a case in point; powerful explosives have allowed men to do admirable work. They are also a terrible means of destruction in the hands of the great criminals who lead peoples into war. I am among those who think with Nobel that humanity will derive more good than bad from new discoveries."

Ernest Rutherford was to receive the Nobel Prize in Chemistry in 1908, and in 1911, Marie Curie received a second Nobel Prize, also in chemistry, for the separation of radium and the determination of its properties.

\section{Early Applications}

Radioactivity allowed us to "see" the interior of the atom, to observe for the first time particles emitted one-by-one. It eventually became a well-established test-bed for special relativity and quantum mechanics, providing confirmation of theoretical predictions.

In June 1901, after learning that Walkhoff and F. Giesel in Germany had observed the physiological effect of radiation from radioactive substances using their own skin, Pierre Curie placed a radium source for 10 hours on his own arm in order to determine the injury that resulted. Starting with these observations, he transmitted his results to doctors in the Saint-Louis Hospital in Paris, prompting them to treat various skin diseases with radiation. This was the beginning of "curietherapy".

Pierre Curie and André Laborde observed in 1903 that radium continuously released heat, and that the quantity released during one hour amounted to more than was needed to melt its own weight of ice. By 1903 , it was generally recognized that minute quantities of radioactive elements were present in almost all of the minerals that made up the Earth's crust. Rutherford noted that this represented a huge amount of radioactive matter, and, in a state of thermal equilibrium, the heat supplied by radioactivity would help compensate that lost by radiation. This could explain why the Earth had stayed at about the same temperature for a very long time, thus allowing the development of life.

On Rutherford's suggestion, the American physicist and mining engineer B.B. Boltwood performed in $1904-5$ the first measurements, on the basis of the helium content, of the age of rocks containing uranium minerals, and, two years later, on the basis of the ratio of their lead to uranium content. Ages of 400 to 2200 million years were established for certain primary minerals. Like many studies and discoveries involving radioactivity, these geological measurements took place several years before the discovery of the atomic nucleus.

\section{References}

[1] Becquerel H., C.R. Acad. Sci. Paris 122 (1896) 420. [2] Becquerel H., C.R. Acad. Sci. Paris 122 (1896) 501.

[3] Curie M.S., C.R. Acad. Sci. Paris 126 (1898) 1101.

[4] Curie P. \& Curie M.S., C.R. Acad. Sci. Paris 127 (1898) 175.

[5] Curie P., Curie M.S. \& Bémont G., C.R. Acad. Sci. Paris 127 (1898) 1215.

[6] Rutherford E. \& Soddy F,, Phil. Mag.S6 4 (1902) 370, 569 .

[7] Rutherford E. \& Soddy F, Phil. Mag. S65(1903) 576. 